\title{
Prevalence of severe visual impairment and barriers to access eye care services in the Udupi district
}

\author{
Lavanya G. Rao', Dushyant Sharma², Sulatha V. Bhandary³, Divya \\ Handa $^{3}$, Yogish Kamath ${ }^{3}$ \\ ${ }^{1}$ Department of Ophthalmology, Dr. AV Baliga Memorial Hospital, \\ Doddanagudde, Udupi, India; ${ }^{2}$ Eye Care Eye Hospital, Noida, India; ${ }^{3}$ Department \\ of Ophthalmology, Kasturba Medical College, Manipal Academy of Higher \\ Education, Manipal, India
}

\begin{abstract}
Aim: To assess the prevalence of severe visual impairment (SVI) and reasons for not accessing eye care services in a field practice area of a tertiary care hospital.

Study design: Cross-sectional observational study.

Materials and methods: Through a cross-sectional study using simple random sampling, a total of 1510, individuals above 18 years of age, from six rural and maternity welfare centers (RMCW) within a distance of $20 \mathrm{~km}$ from a tertiary hospital were approached. All participants underwent basic assessment of visual acuity, anterior segment evaluation using torch light, and answered a structured questionnaire on eye care.

Results: Of 1510 subjects, 267 had SVI (defined as visual acuity < 6/60 either in one or both eyes) with a prevalence of $17.7 \%$. SVI was higher among men and those above 60 years of age (52.8\%). Significant association was found between barriers to accessing eye care facilities and lack of knowledge to access health care $(p=0.004)$, lack of financial support (95\% Cl, $p=0.006)$, and social reasons (95\% Cl, $p=0.028)$. Prevalence of SVI among diabetics was $32.7 \%$ as compared to non-diabetics (OR: 2.630; 95\% confidence interval: 1.864-3.712), and among hypertensives was $34.61 \%$ as compared to non-hypertensives (OR: 2.836; 95\% confidence interval: 1.977-4.068).

Conclusion: In spite of being close to a tertiary care center, a prevalence of SVI in $17.7 \%$ of this population indicates a lack of knowledge regarding the importance of self-health care in subjects. This emphasizes the need to increase the awareness among the general public to access the ophthalmic health care facilities in order to improve the ocular health of the patients.
\end{abstract}

Keywords: barriers to access eye care services, house-to-house screening, lack of knowledge, severe visual impairment, social burden

Correspondence: Sulatha V. Bhandary, Professor and Head, Department of Ophthalmology, Kasturba Medical College, Manipal 576104, Karnataka, India.

E-mail: sulatha.bhandary@manipal.edu 


\section{Introduction}

According to a 2010 World Health Organization report on visual impairment (VI) in India, approximately 62.6 million people are visually impaired, 8.01 million are blind, and 54.5 million have low vision. ${ }^{1}$ A meta-analysis by Flaxman et al., ${ }^{2}$ as well as other studies, ${ }^{3}$ have shown that, as the population increases and ages, common causes of $\mathrm{VI}$ are cataract and refractive errors, which are seen more in rural areas. Moreover, in India, more than $80 \%$ patients with cataract blindness who were advised surgery did not take the advice over a 2-year follow-up period because of economic or social constraints. ${ }^{4,5}$

In studies on the impact of successful cataract surgery on quality of life conducted in India, Shamanna et $a .^{6}$ and Finger et al. ${ }^{7}$ found that overall quality of life improved for patients after cataract surgery. Despite the advantage of free health and eye care services, the majority of Indians living in rural areas are less likely to use eye care services and are more likely to suffer disability-adjusted life years and heavier economic loss. ${ }^{6,8-10}$ The reasons for not accessing eye care services are good vision in the other eye, a feeling that there is no need for surgery, a belief that in older age $\mathrm{VI}$ is known to happen, fear of surgery, expenses, and lack of caretakers to accompany to the hospital.

$\mathrm{VI}$ is a significant public health problem in many parts of the world, including the Indian state of Karnataka. ${ }^{11}$ To our knowledge, there has been no systematic study on the prevalence of $\mathrm{VI}$ and the perceived barriers to access eye care services in the rural areas of the Udupi district, in the state of Karnataka, India. In this study, we aim to provide a snapshot on the prevalence of $\mathrm{VI}$ and the reasons for not utilizing eye care services in the areas of six rural and maternity welfare centers (RMCW) attached to a tertiary care center by conducting a house-tohouse survey.

\section{Materials and methods}

This is cross-sectional study included the rural population above 18 years of age living in the areas of RMCW centers attached to a tertiary care hospital situated in the Udupi district of the state of Karnataka. The study was approved by the Institutional Ethics Committee of Kasturba Medical College and followed the Declaration of Helsinki.

The population of the Udupi district is approximately 1.18 million. ${ }^{11}$ The total population covered by the six RMCW centers is 46,856 , with those above 18 years of age being 38,308. All the RMCW centers were located within $20 \mathrm{~km}$ from the base hospital. Based on a pilot study conducted by the principal investigator which anticipated a proportion of $\mathrm{VI}$ of $12.3 \%$ in the population, with a relative precision of 15 at $95 \%$ confidence, the calculated minimum sample size was 1,217 individuals. A total of 1,510 individuals above 18 years of age residing in homes in 
the area covered by the RMCW centers were included in the study using a simple random sampling method.

The RMCW centers are managed by auxiliary nurse midwives (ANMs) who have close relationships with the population. The RMCW centers were established 40 years ago and the ANMs were employed to develop a positive interaction with the villagers. They act as a link between the tertiary care center and the villagers. ANMs have house lists of all village residents; all residents were enrolled in the ANMs' list. The villagers were informed well in advance to be at home on the given dates to take part in the study, which was a house-to-house survey. The principal investigator and assistants visited each house. The assistants were sixth semester medical students posted in the Department of Ophthalmology, Kasturba Medical College. After undergoing 2 weeks of training to assess visual acuity (VA), they were posted for the survey under the guidance of a final year postgraduate student. ANMs were recruited for help, as they were aware of the exact location and number of residents of each house.

The questionnaire on eye care services was prepared by the principal investigator (Annex 1). The contents were validated by three ophthalmologists and a statistician. The approved questionnaire was translated into the local language (Kannada) and the translation was validated by retranslation into English.

Written informed consent was obtained from all participants. All the subjects included in the study answered the questionnaire. The questionnaire probed into the reasons for not accessing eye care services, which were mainly lack of self-awareness of $\mathrm{VI}$, lack of an accompanying person for medical visits, financial burden, and social burden.

All the participants underwent a brief ophthalmological examination. VA was checked using the Snellen chart (including the illiterate E cards whenever necessary) to evaluate whether participants were able to see the top letter on the chart at a distance of 6 meters in good day light. The aim was to identify individuals having SVI, defined as VA less than 6/60. In those who had spectacles, VA was assessed with the spectacles; in those who did not have spectacles, unaided VA was recorded. Whether with or without spectacles, the aim was to find out how many individuals were leading their lives with SVI. The data was entered and analyzed using Statistical Package for Social Sciences (SPSS) version 15. A $p$-value less than 0.05 was taken as significant.

Since our study focused on assessing the prevalence of SVI and the reasons for not accessing eye care facilities, the causes of SVI, pinhole test, and refraction were not examined. The subjects who were found to have SVI were later called to RMCW centers for complete evaluation. However, the results of those examinations are not a part of this present study. A further study to assess these items is planned and will be published later. 


\section{Results}

A total of 1,510 individuals who were above 18 years of age were approached from six RMCW center areas. Of the 1,510 subjects examined, $43 \%$ of the subjects were $18-44$ years of age, $28.2 \%$ were $45-60$ years of age, and $28.8 \%$ were over 60 years of age. Among the total subjects examined, $63.18 \%$ were females and $36.82 \%$ were males. The majority $(41.4 \%)$ of subjects had academic qualifications between grades 5-10. The demographic characteristics of the population are summarized in Table 1.

Table 1. Sociodemographic characteristics of the subjects

\begin{tabular}{|c|c|}
\hline Variables & $n(\%)$ \\
\hline \multicolumn{2}{|l|}{ Age group (years) } \\
\hline $18-44$ & $650(43 \%)$ \\
\hline $45-60$ & 425 (28.2\%) \\
\hline$>60$ & 435 (28.8\%) \\
\hline \multicolumn{2}{|l|}{ Gender } \\
\hline Female & 954 (63.2\%) \\
\hline Male & $556(36.8 \%)$ \\
\hline \multicolumn{2}{|l|}{ Education } \\
\hline Illiterate & $96(6.4 \%)$ \\
\hline Grades 1-5 & 202 (13.4\%) \\
\hline Grades 5-10 & 625 (41.4\%) \\
\hline Grades 11-12 & 277 (18.3\%) \\
\hline Higher education & 310 (20.5\%) \\
\hline
\end{tabular}

\section{Prevalence of SVI}

SVI, i.e., visual acuity less than 6/60 either in one or both eyes was noted in 267 $(17.7 \%)$ subjects. Monocular SVI was found in $8.8 \%$ of subjects and binocular SVI was found in $8.9 \%$ of subjects.

\section{Correlation of SVI with gender and age}

Among 267 subjects who had SVI, 159 (59.55\%) were females. By taking the gender proportion of the specified population into consideration, approximately $16.6 \%$ of women and $19.4 \%$ of men suffered SVI. The prevalence of SVI was greater in 
individuals above 60 years of age (52.81\%) when compared to the $18-44(14.23 \%)$ and $45-60$ age groups (32.96\%).

\section{Correlation of SVI with education level and employment status}

Details about the education level of all participant subjects and presence or absence of SVI are shown in Table 2. There was greater prevalence of SVI among the group with less than 10 years of schooling (79\%) when compared to the group with more than 10 years of schooling (21\%); this was statistically significant $p=0.000$ (Table 3).

There was no statistically significant association between the presence of SVI and level of employment. Of 654 subjects in the employed group, SVI was noted in 66; of the 589 subjects in the unemployed group subjects, SVI was noted in 67.

Table 2. Education level of all participant subjects versus presence or absence of severe visual impairmentt

\begin{tabular}{|l|l|l|l|l|}
\hline $\begin{array}{l}\text { Academic } \\
\text { qualifications }\end{array}$ & No SVI* & $\begin{array}{l}\text { Monocular } \\
\text { SVI* }\end{array}$ & $\begin{array}{l}\text { Binocular } \\
\text { SVI* }\end{array}$ & Total \\
\hline Illiterate & 62 & 20 & 14 & 96 \\
\hline Grades 1-5 & 154 & 18 & 30 & 202 \\
\hline Grades 5-10 & 496 & 56 & 73 & 625 \\
\hline Grades 11-12 & 246 & 21 & 10 & 277 \\
\hline Higher education & 285 & 18 & 7 & 310 \\
\hline Total & 1,243 & 133 & 134 & 1,510 \\
\hline
\end{tabular}

SVI defined as visual acuity $<6 / 60$

SVI: severe visual impairment

Table 3. Severe visual impairment versus years of schooling $(n=267)$

\begin{tabular}{|l|l|l|l|}
\hline Years of schooling & Monocular SVI* & Binocular SVI* & Chi-square test \\
\hline $\begin{array}{l}>10 \text { years of } \\
\text { schooling }\end{array}$ & $39(14.6 \%)$ & $17(6.4 \%)$ & \multirow{2}{*}{0.0000} \\
\hline $\begin{array}{l}<10 \text { years of } \\
\text { schooling }\end{array}$ & $94(35.2 \%)$ & $117(43.8 \%)$ & \\
\hline
\end{tabular}

SVI defined as visual acuity $<6 / 60$

SVI: severe visual impairment

\section{Self-awareness about SVI}

Of the 267 subjects with SVI, 61.04\% were aware of their SVI. However, they did not seek any treatment or ocular examination. 


\section{SVI and systemic disease association}

Of 1,510 subjects examined, 180 (11.92\%) were diabetic. Of the 267 subjects with SVI, 59 (22.1\%) were diabetic. Prevalence of SVI among diabetics was $32.7 \%$, while in non-diabetics it was $15.6 \%$. This was statistically significant (odd ratio: 2.630; 95\% confidence interval: 1.864-3.712).

Similarly, of the 1,510 subjects examined 156 (10.33\%) were hypertensive. Of the 267 subjects having SVI, 22.2\% were hypertensives. The prevalence of SVI among hypertensives was found to be $34.61 \%$, while among non-hypertensives it was $15.73 \%$, which was also statistically significant (odd ratio: $2.836 ; 95 \%$ confidence interval: 1.977-4.068).

\section{Reasons for not accessing of eye care services}

Among the 267 subjects who were found to have SVI, the main reasons given for not accessing eye care services were: lack of knowledge to access health care $(50.19 \%, n=134)$, lack of accompanying person $(34.83 \%, n=93)$, lack of financial support $(8.61 \%, n=23)$, and lack of social support $(6.37 \%, n=17)$. (Table 4$)$.

When analyzing non-utilization of eye care services in relation to education status, we found that there was a significant association between less than 10 years of schooling and lack of knowledge to access health care $(p=0.004)$, lack of social support $(p=0.028)$, and lack of financial support $(p=0.006)$ (Table 5$)$.

\section{Discussion}

Approximately 285 million people are visually impaired worldwide: $90 \%$ of the visually impaired live in developing countries. ${ }^{1}$ Even though $80 \%$ of all $\mathrm{VI}$ can be avoided or cured, the prevalence of blindness in the population aged 50 years and above is $8.5 \%$. The top two causes of VI impairment worldwide are uncorrected refractive errors and unoperated cataract. ${ }^{12}$ Cataract surgery has a positive impact on the quality of life and income of the patients. ${ }^{13,14}$, In India, the prevalence of blindness in the general population is $1.1 \% .^{15}$

Table 4. Reasons for not accessing eye care services among subjects with severe visual impairment

\begin{tabular}{|l|l|}
\hline Reasons & $\mathbf{N}(\%)$ \\
\hline Lack of knowledge to avail health care facility & $134(50.19 \%)$ \\
\hline Lack of accompanying person & $93(34.83 \%)$ \\
\hline Financial burden & $23(8.61 \%)$ \\
\hline Social burden & $17(6.37 \%)$ \\
\hline Total & 267 \\
\hline
\end{tabular}

SVI: severe visual impairment 
Table 5. Association between barriers for eye care versus years of schooling

\begin{tabular}{|l|l|l|l|l|}
\hline Reasons & $\begin{array}{l}>10 \text { years } \\
\text { of } \\
\text { schooling }\end{array}$ & $\begin{array}{l}<10 \\
\text { years of } \\
\text { schooling }\end{array}$ & OR (CI) & P-value \\
\hline Financial burden & 0 & 23 & $\begin{array}{l}1.122 \\
(1.072-1.177)\end{array}$ & 0.006 \\
\hline $\begin{array}{l}\text { Lack of accompanying } \\
\text { person }\end{array}$ & 18 & 75 & $\begin{array}{l}0.904 \\
(0.593-1.379)\end{array}$ & 0.753 \\
\hline Social burden & 0 & 17 & $\begin{array}{l}1.082 \\
(1.041-1.125)\end{array}$ & 0.028 \\
\hline $\begin{array}{l}\text { Lack of knowledge to } \\
\text { avail health care facility }\end{array}$ & 38 & 96 & $\begin{array}{l}1.491 \\
(1.181-1.883)\end{array}$ & 0.004 \\
\hline
\end{tabular}

$p<0.05$ is considered significant

$\mathrm{Cl}$ : confidence interval; OR: odds ratio; SVI: severe visual impairment

Our study found that, in spite of being close to a tertiary care hospital, availability of primary and secondary level of care nearby, and many awareness programs being conducted in this area, $17.7 \%$ of subjects were found to have SVI, i.e., visual acuity less than $6 / 60$ or inability to count fingers at 6 meters in one or both eyes. Other studies in comparable populations, such as by Zhang et al. ${ }^{16}$ and Srinivisan et al. ${ }^{17}$ found much lower prevalence of SVI at $0.9 \%$ and $0.8 \%$, respectively.

Our study showed that SVI was more prevalent among males and those aged 60 years or more. A study conducted by Singh et al. showed similar results, ${ }^{18}$ as did Zhang et al, who also found a higher prevalence of SVI in individuals above 50 years of age, but contrary to our study, found higher SVI prevalence among females. ${ }^{16}$

In this study, the single most important reason for not accessing eye care was lack of knowledge to avail health care facility among those who had SVI (50.19\%), followed by $34.83 \%$ who had no accompanying person, lack of financial support $(8.6 \%)$, and lack of social support/social reasons (5.9\%) such as taking care of grandchildren and other social responsibilities like attending functions and performing other household activities, etc.).

In our study, of the 267 subjects with SVI, $61.04 \%$ were aware of their SVI. However, they did not seek any treatment or ocular examination. Of these, almost $50.19 \%$ did not have the knowledge to access ophthalmic health care facilities.

Lack of knowledge included the following misconceptions: poor vision is a part of ageing and so individuals are expected to live with it; in case they opt for eye checkup, fear that their visual complaints will be revealed to others; lack of knowledge about whom to approach for their visual complaints, which also 
included fear of losing existing vision if they opt for surgical treatment for their ocular condition.

Another compelling reason for not accessing health care service was lack of accompanying person. Most of the families are working couples, so elderly individuals do not have someone to bring them to the hospitals on weekdays. Hence, most of them postponed their eye checkup. Lack of joint family system and young family members working in distant places (away from home) are some of the reasons for the above problem.

Although the district's blindness control society and a non-governmental organization run camps accommodate the accompanying person and reduce the financial burden on the patients, our study showed that $8.61 \%$ informed that they did not avail the free treatment due to the financial burden. On questioning, they explained that they have to spend on the accompanying person's food, the accompanying person loses their pay during the hospital stay as most of them are daily wagers, and other family members need to take time off from their duties to take care of the children at home. All these together cause a significant financial burden on the family.

Lastly, around $5.9 \%$ did not avail the health care facility due to social reasons. For example, many elderly individuals had to take care of pregnant or postpartum women and children whose parents were away for work. Some also have the misconception that locking the house is a bad omen: some houses have daily deity worship, which goes against locking and leaving the house.

We find it notable that, even with available primary, secondary, and tertiary health services in the vicinity that may be accessed for free, almost $61.4 \%$ of the participants who were aware of their SVI had not sought treatment, which is similar to the reported urban data of Andra Pradesh Eye Disease Study (APEDS). ${ }^{19}$ This might be due to the health-seeking priorities in relation to age in rural areas, as many believe that visual impairment is a part of aging and nothing can be done about it. However, our study uncovers that, in addition to the idea that VI is to be accepted as a normal part of aging, there are other powerful factors at play. A similar study by Srinivasan et al. showed that person-related barriers to undergo cataract surgeries were lack of perceived need (for reasons such as old age, good vision in other eye) and lack of accompanying person. The service-related barriers were lack of affordability and accessibility. ${ }^{17}$

Our analysis also clearly shows that the majority of the rural population under study with less than 10 years of schooling did not seek eye care mainly due to lack of knowledge about availing health care facility, as well as the economic and social burden of accessing ophthalmic care. Less than 10 years of schooling had a statistically significant association with the prevalence of SVI. 


\section{Strengths and limitations}

The main strength of our study lies in providing a snapshot of SVI prevalence for certain areas of the Udupi district as well as outlining key factors that prevent individuals with SVI from accessing eye care. The main limitation is that the study sample covered various RMCW centers, and therefore is not representative of the whole district. In addition, we did not examine the causes of SVI, which will be outlined in further planned studies. However, we believe the data presented in this study may provide a foothold for a larger cluster-sampled data collection, which is required to plan future public health interventions.

To conclude, our study captured a snapshot of SVI prevalence of visual impairment in the Udupi district of southern India and identified the factors preventing individuals from accessing ophthalmic care. The observation that economic and social reasons are important for not seeking treatment for the subjects included in the study leads us to conclude that, in order to increase the uptake of services, there is a need to understand the link between social and economic factors and impact of direct and indirect costs on seeking treatment in the social context of rural people. Hence, it is recommended that, a comprehensive framework be evolved to provide health care facility in rural areas, which should include community education regarding eye check-ups and a well-established referral system.

\section{Declarations}

\section{Competing interests}

None to declare.

\section{Funding}

None to declare.

\section{Acknowledgements}

The authors wish to acknowledge the $6^{\text {th }}$ semester MBBS students, the Department of Community Medicine and Biostatistics, and the ANMs at the Rural and Maternal Child Welfare homes for their help in conducting the study. We thank the Kasturba Medical College Hospital Manipal for arranging the transport to the RMCW homes. 


\section{Annex 1. Questionnaire used in the study.}

Prevalence of severe visual impairment in age group $>18$ years and barriers to access eye care services in a field practice area of KMC, Manipal in Udupi District of Karnataka. A survey by the Department of Ophthalmology, KMC Manipal.

\section{PART A}

NAME:

AGE:

SEX:

CASTE:

OCCUPATION:
ADDRESS:

CONTACT NO:

DIETARY HABITS: Vegetarian/Non-vegetarian ACADEMIC QUALIFICATIONS:

ECONIMIC STATUS:

\section{PART B}

1. Which statement best describes your vision?
(a) Excellent
(b) Good
(c) Fair
(d) Poor
(e) Unable to see

2. Do you use eyeglasses/contact lenses?
(a) Yes
(b) No

3. Do you have a history of any of the following eye problems?
(a) Cataract
(b) Glaucoma
(c) Color blindness
(d) No

4. Have you noticed any decrease in vision in the last 5 years?
(a) Yes
(b) No

5. Are you of the opinion that decreased vision is natural with old age?
(a) Yes
(b) No

6. If yes, do you think treatment is not REQUIRED in such instances?
(a) Yes
(b) No

7. Are you worried that seeing someone for an eye check-up would reveal vision loss?
(a) Yes
(b) No

8. Do you know where and to whom to approach for eye check-ups?
(a) Yes
(b) No 
9. Do you have to travel far for an eye check-up?
(a) Yes
(b) No

10. Do you feel that an eye check-up is not a priority because of other serious medical problems?
(a) Yes
(b) No

11. Do you feel that you would like you have an eye check-up, but other medical problems prevent you from going for an eye check-up?
(a) Yes
(b) No

12. Are you afraid of surgery?
(a) Yes
(b) No

13. Is lack of finance the reason for not going for eye check-up?
(a) Yes
(b) No

14. Is lack of an accompanying person preventing you from getting an eye check-up?
(a) Yes
(b) No

15. Are family/business /other commitments reasons that prevent you from having an eye check-up?
(a) Yes
(b) No

16. Is it because the dominant family member does not feel there is a need for an eye check-up for other family members, especially elderly members?
(a) Yes
(b) No

17. Do you feel that a lot of time is taken in tertiary eye care hospital for eye check-ups?
(a) Yes
(b) No

18. Do you feel that students perform the examination rather than consultants?
(a) Yes
(b) No

19. Do you have any significant systemic illness?
(a) Yes
(b) No 
20. If YES, then specify the type of illness and duration:

- Diabetes

- Hypertension

- Anemia

- Others

21. If YES to any of the above illness, have you undergone an eye check-up in:

- The last two years

- The last five years

- Never had a check-up

- Don't think it is required to do so

\section{PART C}

Vision: (RE)

For those who have severe visual impairment in any eye:

- Visual axis:

- Extraocular movements:

- Anterior segment (torch light examination)

IMPRESSION: (CAUSE OF VISUAL IMPAIRMENT):

- Cataract

- Corneal blindness

- Others:

ADVICE TO PATIENT: 


\section{References}

1. World Health Organization. Global data on visual impairments 2010. WHO Press;2010. Available from: http://www.who.int/blindness/GLOBALDATAFINALforweb.pdf.

2. Flaxman SR, Bourne RRA, Resnikoff $S$, et al. Global causes of blindness and distance vision impairment 1990-2020: a systematic review and meta-analysis. Lancet Glob Health. 2017;5(12):e1221-e1234. https://doi.org/10.1016/S2214-109X(17)30393-5. Epub: 2017 Oct 11.

3. Thylefors B. A simplified methodology for the assessment of blindness and its main causes. World Health Stat Q. 1987;40(2):129-141. Available from: https://apps.who.int/iris/ handle/10665/48330.

4. Venkataswamy G, Brilliant $\mathrm{G}$. Social and economic barriers to cataract surgery in rural south India. A preliminary report. Visual Impairment Blindness. 1981;405-68.

5. Morgan M, Calnan M, Manning N. Sociological approaches to health and illness. Beckenham; Croom Helm: 1985.

6. Shamanna BR, Dandona L, Rao GN. Economic burden of blindness in India. Indian J Ophthalmol. 1998;46(3):169-172.

7. Finger RP, Kupitz DG, Fenwick E, et al. The impact of successful cataract surgery on quality of life, household income and social status in South India. PLoS One. 2012;7(8):e44268. https://doi. org/10.1371/journal.pone.0044268. Epub: 2012 Aug 31.

8. Brilliant GE, James M, Lepakowski, Zurita B, Thulsiraj RD. Social determinants of cataract surgery. The Operations Research Group. Arch Ophthalmol 1991;109:584-589.

9. Censusindia.net. Available from: http://www.censusindia.net/results/summaryindia.html.

10. Balasubramanian D, Bhat KD, Rao GN. Factors in the prevalence of cataract in India: Analysis of a recent Indo-US study of age-related cataracts. Curr Sci. 1990;59:498-505.

11. Government of India. Census of India. Available from: http://www.censusindia.gov.in/2011prov_results/prov_data_products_karnatka.html.

12. World Health Organization. Blindness and visual impairment. 2017 World Sight Day. Available from: https://www.who.int/blindness/world_sight_day/2017/en/

13. Vijaykumar V, John RK, Datta D, Tulasiraj RD, Nirmalan PK. Quality of life after community-based rehabilitation for blind persons in a rural population of South India. Indian J Ophthalmol. 2004;52(4):331-335.

14. Marmamula S, Khanna RC, Shekhar K, Rao GN. A population-based cross-sectional study of barriers to uptake of eye care services in South India: The Rapid Assessment of Visual Impairment (RAVI) project. BMJ Open. 2014;4(6):e005125. https://doi.org/10.1136/bmjopen-2014-005125.

15. National Programme for Control of Blindness and Visual Impairment by Government of India. Available from: https://dghs.gov.in/content/1354_3_ NationalProgrammeforControlofBlindnessVisual.aspx.

16. Zhang G, Tham $\mathrm{YC}$, Gong H, et al. Blindness, low vision and cataract surgery outcome among adults in Hohhot of Inner Mongolia: A Rapid Assessment of Avoidable Blindness (RAAB) study. $\mathrm{Br}$ J Ophthalmol. 2018;102(12):1653-1657. https://doi.org/10.1136/bjophthalmol-2017-311633

17. Srinivasan S, Swaminathan G, Kulothungan V, Raman R, Sharma T. Prevalence and the risk factors for visual impairment in age-related macular degeneration. Eye (Lond). 2017;31(6):846-855.

18. Singh MM, Murthy GV, Venkatraman R, Rao SP, Nayar S. A study of ocular morbidity among elderly population in a rural area of central India. Indian J Ophthalmol. 1997;45(1):61-65.

19. Dandona R, Dandona L, Naduvilath TJ, McCarty C, Rao GN. Utilization of eye care services in an urban population in southern India. Br J Ophthalmol. 2000;84:22-27. 